\title{
Development and Validation of Spectrophotometric and Spectrofluorimetric Methods for the Determination of Cyclobenzaprine $\mathrm{HCl}$
}

\section{Ramadan NK ${ }^{1}$, Mohamed TA ${ }^{2}$, Fouad RM $^{2^{*}}$ and Moustafa AA ${ }^{1}$}

${ }^{1}$ Department of Analytical Chemistry, Faculty of Pharmacy, Cairo University, Giza, Egypt

${ }^{2}$ Department of Pharmaceutical Chemistry, National Organization for Drug Control and Research, 9 Abou-Hazem str, Giza, Egypt

\begin{abstract}
Five simple and sensitive methods were developed for the determination of cyclobenzapirine hcl (CB) in presence of its degradation product anthraquinone $(A Q)$.

Method A dual wavelength spectrophotometry (DW); where two wavelengths were selected for the drug 283 and $306 \mathrm{~nm}$ in such a way that the difference in absorbance was zero for its degradation. Method $B$ ratio difference spectrophotometry (RD) was depended on measuring the ratio difference between 290 and $305 \mathrm{~nm}$. Method C was depended on measuring the peak amplitude of the first derivative of the ratio spectra ('DD) at 282 and 306 $\mathrm{nm}$. Method D Isoabsorptive Point (ISO) at $280 \mathrm{~nm}$ Coupled with Second Derivative $\left({ }^{2} \mathrm{D}\right)$. Method E depending on spectrofluorimetric determination of cyclobenzapirine $\mathrm{HCl}$ through quenching of uranyl acetate with $\Lambda_{\text {exi }} 228 \mathrm{~nm}$ and $\Lambda_{\mathrm{e}}$ at $458 \mathrm{~nm}$. Linearties were obtained in concentration range $5 \mu \mathrm{g} / \mathrm{ml}-30 \mu \mathrm{g} / \mathrm{ml}$ in case of methods $\mathrm{A}, \mathrm{B}$, $C$ and $D$, while in case of methods $E$ linearity was obtained in concentration range of $1 \mu \mathrm{g} / \mathrm{ml}-10 \mu \mathrm{g} / \mathrm{ml}$. The five methods were found to be specific for $\mathrm{CB}$ in presence of different concentration $\%$ of its degradation product. The five proposed methods were successfully applied for the determination of CB in Multirelax tablets. Statistical comparison between the results obtained by the proposed methods and that obtained by the official one for the determination of the drug was done, founding that there were no significant differences between them.
\end{abstract}

Keywords: Cyclobenzapirine $\mathrm{HCl}(\mathrm{CB})$; Anthraquinone (AQ); Dual wavelength (DW); Ratio difference (RD); ( $\left.{ }^{1} \mathrm{DD}\right)$ Derivative ratio; Isoabsorptive point (ISO); Spectrofluorimetry; Uranyl acetate

\section{Introduction}

Cyclobenzaprine hydrochloride [3-(5H-dibenzo [a, d] cyclohepten5 -ylidene)-N-N-dimethyl-1-propanamine hydrochloride; (CB) is a centrally acting muscle relaxant and related to tricyclic antidepressent. It is used in the treatment of the muscloskeletal condition which associated with painful muscle spasms [1]. The determination of CB is described in the U.S.P. [2] by non-aqueous titration method. It is also determined by several methods involving spectrophotometry [3-6], TLC $[7,8]$, different HPLC methods using several mobile phases [9-14], HPLC coupled with MS detection [15-22] and GC-MS [23-26]. Five stability-indicating methods were reported for the determination of $\mathrm{CB}$ in the presence of its degradation product [27-31].

The present study describes simple, sensitive and precise stabilityindicating spectrophotometric and spectrofluorimetric procedures for the quantitative determination of $\mathrm{CB}$ in pure form, pharmaceutical formulation and in the presence of AQ (its degradation product) AQ. These methods are developed and validated according to ICH guidelines [32] for the determination of the chosen drug. There are many advantages of the proposed methods as low cost, rapidity and environmental protection which suitable for quality control laboratories where economy and time are essential.

\section{Materials and Methods}

\section{Instruments}

-UV-Visible spectrophotometer (Unicam UV 300, Kyoto, Japan).

Spectrofluorimeter (Agilant Technologies, Cary Eclipse Fluorescence, Australia).

\section{Sample}

Reference sample: Pure sample CB was kindly supplied by Multi-
Apex Pharma, Badr City, Cairo, Egypt (Batch No. mt4431014). According to the pharmacopeia method [2] its purity was found to be $99.50 \pm 0.33 \%$.

Pharmaceutical formulation: Multi-Relax tablets, (Batch No $\mathrm{CBP} / 1506004-\mathrm{M})$, claimed to contain $10 \mathrm{mg} \mathrm{CB}$, manufactured by Multi-Apex Pharma Company for Pharmaceutical Industries, purchased from a local market.

Degraded sample: Anthraquinone (AQ), a degradation product of CB was purchased from Sigma-Aldrich (St. Louis, MO).

\section{Reagents}

-Methanol of analytical grade (Fischer scientific - UK)

- Distilled water

-Uranyl acetate (Fluka Chemie GmbH- Germany.) $0.25 \times 10^{-3} \mathrm{~mol}$ freshly prepared in distilled water.

\section{Stock and working solutions}

$C B$ Stock and working solutions:

-Methods (A), (B), (C) and (D)

CB stock standard solution of $(1 \mathrm{mg} / \mathrm{mL})$ in methanol was prepared

*Corresponding author: Rowayda M Fouad, Department of Pharmaceutical Chemistry, National Organization for Drug Control and Research, 9 Abou-Hazem str, Giza, Egypt, Tel: +202-35851299; E-mail: dr_rodi225@yahoo.com

Received January 06, 2018; Accepted January 20, 2018; Published January 29, 2018

Citation: Ramadan NK, Mohamed TA, Fouad RM, Moustafa AA (2018) Development and Validation of Spectrophotometric and Spectrofluorimetric Methods for the Determination of Cyclobenzaprine $\mathrm{HCl}$. Pharm Anal Acta 9: 574. doi: 10.4172/2153-2435.1000574

Copyright: (c) 2018 Ramadan NK, et al. This is an open-access article distributed under the terms of the Creative Commons Attribution License, which permits unrestricted use, distribution, and reproduction in any medium, provided the original author and source are credited. 
Citation: Ramadan NK, Mohamed TA, Fouad RM, Moustafa AA (2018) Development and Validation of Spectrophotometric and Spectrofluorimetric Methods for the Determination of Cyclobenzaprine HCl. Pharm Anal Acta 9: 574. doi: 10.4172/2153-2435.1000574

by dissolving $25 \mathrm{mg}$ of $\mathrm{CB}$ in a $25-\mathrm{mL}$ volumetric flask, and then the volume was completed to the mark with methanol. An aliquot of the prepared stock solution was further diluted with the methanol solvent to get a working solution with final concentration $(0.25 \mathrm{mg} / \mathrm{mL})$.

-Method (E)

CB stock standard solution of $(1 \mathrm{mg} / \mathrm{mL})$ in water was prepared by dissolving $25 \mathrm{mg}$ of $\mathrm{CB}$ in a $25-\mathrm{mL}$ volumetric flask, and then the volume was completed to the mark with water. An aliquot of the prepared stock solution was further diluted with the suitable solvent to get a working solution with final concentration $(0.1 \mathrm{mg} / \mathrm{mL})$.

Stock and working solutions of $A Q$ (degradation product of $\mathrm{CB})$ :

-Methods (A), (B), (C) and (D)

AQ standard solution of $(1 \mathrm{mg} / \mathrm{mL})$ in methanol by dissolving $25 \mathrm{mg}$ of $\mathrm{AQ}$ in a $25-\mathrm{mL}$ volumetric flask, and then the volume was completed to the mark with methanol. An aliquot of the prepared stock solution was further diluted with methanol to get a working solution with final concentration $(0.25 \mathrm{mg} / \mathrm{mL})$.

-Method (D)

AQ standard solution of $(0.1 \mathrm{mg} / \mathrm{mL})$ in water by dissolving $2.5 \mathrm{mg}$ of $\mathrm{AQ}$ in a $25-\mathrm{mL}$ volumetric flask, and then the volume was completed to the mark with water.

Laboratory prepared mixtures containing different ratios of $\mathrm{CB}$ and $A Q$ :

-Methods (A), (B), (C) and (D):

Aliquots $(1-0.2 \mathrm{~mL})$ of $\mathrm{CB}$ were accurately transferred from its working solution $(0.25 \mathrm{mg} / \mathrm{mL})$ into a series of $10-\mathrm{mL}$ volumetric flasks equivalent to $(25 \mu \mathrm{g} / \mathrm{ml}-5 \mu \mathrm{g} / \mathrm{mL})$. Aliquots $(0.2-1 \mathrm{~mL})$ of AQ working solution $(0.25 \mathrm{mg} / \mathrm{mL})$ equivalent to $(5 \mu \mathrm{g} / \mathrm{ml}-25 \mu \mathrm{g} / \mathrm{mL})$ were added, the volume was completed with methanol.

-Methods (E):

Aliquots $(0.9-0.1 \mathrm{~mL})$ of CB working standard solution $(0.1 \mathrm{mg} /$ $\mathrm{mL})$ equivalent to $(90-10 \mu \mathrm{g})$ were accurately transferred into a series of $10-\mathrm{mL}$ volumetric flasks. Aliquots $(0.1-0.9 \mathrm{~mL})$ of the degradation product working solution $(0.1 \mathrm{mg} / \mathrm{mL})$ equivalent to $(10 \mu \mathrm{g}-90$ $\mu \mathrm{g}$ ) were added, followed by $2.5 \mathrm{~mL}$ of $0.25 \times 10^{-3} \mathrm{~mol}$ uranyl acetate solution then the volumes were completed with water.

\section{Procedures}

\section{Construction of the calibration curve for method (A) (DW)}

Into a series of $10-\mathrm{mL}$ volumetric flasks aliquots $(0.2,0.4,0.6,0.8,1$ and 1.2) of the $\mathrm{CB}$ stock standard solution $(1 \mathrm{mg} / \mathrm{mL})$ were transferred. The volume was then completed to mark with methanol. The zero-order spectra were recorded in the range of $200 \mathrm{~nm}-400 \mathrm{~nm}$. Absorbance values at 283 and 306 were measured. The difference in absorbance of $\mathrm{CB}$ at $283 \mathrm{~nm}$ and $306 \mathrm{~nm}$ (difference is zero for AQ) was plotted against $\mathrm{CB}$ concentration. Then calibration curve was constructed and the regression equation was computed.

\section{Construction of the calibration curve for method (B) (RD)}

The ratio spectra were obtained by dividing the zero order spectra of the prepared solutions on the spectrum of $5 \mu \mathrm{g} / \mathrm{mL}$ of AQ (degradation product). The peak amplitudes of the ratio spectra were measured at $290 \mathrm{~nm}$ and $305 \mathrm{~nm}$. The difference in amplitude of ratio spectra
( $\triangle \mathrm{P} 290-305)$ was plotted against $\mathrm{CB}$ concentration. Then calibration curve was constructed and the regression equation was computed.

\section{Construction of the calibration curves for method (C) ( $\left.{ }^{1} \mathrm{DD}\right)$}

Then the first derivative of the ratio spectra ${ }^{1} \mathrm{DD}$ with $\Delta \lambda=2$ and scaling factor 10 were obtained. The peak amplitudes of the first derivative of the ratio spectra at $282 \mathrm{~nm}$ and $306 \mathrm{~nm}$ were measured. Linear calibration curves were constructed relating the peak amplitude of the first derivative of the ratio spectra at the specified wavelengths to $\mathrm{CB}$ concentrations and the regression equations were computed.

\section{Construction of the calibration curve for method (D) (ISO)}

Aliquots $(0.2,0.4,0.6,0.8,1$ and 1.2$)$ of $\mathrm{CB}$ were separately transferred from its working standard solution $(0.25 \mathrm{mg} / \mathrm{mL})$ into a series of $10-\mathrm{mL}$ volumetric flasks, diluted to volume with methanol. Then aliquots $(0.1,0.2,0.4,0.6,0.8$ and 1$)$ of AQ were separately transferred from its working standard solution $(0.25 \mathrm{mg} / \mathrm{mL})$ into another series of $10-\mathrm{mL}$ volumetric flasks, diluted to volume with methanol. The zero order absorption spectrum $\left({ }^{\circ} \mathrm{D}\right)$ of each dilution was recorded against blank.

For the determination of $\mathrm{AQ}$, the second derivative $\left({ }^{2} \mathrm{D}\right)$ of the scanned spectra of AQ was obtained with $\Delta \lambda=2$ and scaling factor $=10$. The peak amplitudes at $250 \mathrm{~nm}$ were plotted against AQ concentrations and the calibration curve was constructed and the regression equation (1) was computed.

For CB determination, the absorbance of the scanned spectra of $\mathrm{CB}$ was measured at $280 \mathrm{~nm}$ (isoabsorptive point). The calibration curve relating the absorbances at $280\left(\mathrm{~A}_{\text {iso }}\right)$ to $\mathrm{CB}$ concentrations was constructed and the regression equation (2) was computed.

\section{Construction of the calibration curve for method $(\mathrm{E})$}

Into a series of $10-\mathrm{mL}$ volumetric flasks, aliquots $(0.1,0.2,0.4,0.6,0.8$ and $1 \mathrm{~mL}$ ) of CB were separately transferred from its working standard solution $(0.1 \mathrm{mg} / \mathrm{mL})$ followed by $2.5 \mathrm{~mL}$ of $0.25 \times 10^{-3} \mathrm{~mol}$ uranyl acetate solution then the volumes were completed with water. The fluorescence intensity was measured at $\lambda_{e m} 458 \mathrm{~nm}$ with $\lambda_{\mathrm{ex}} 228 \mathrm{~nm}$ at room temperature $\left(25^{\circ} \mathrm{C}\right)$ against blank similarly prepared. The calibration curve was constructed relating the difference in fluorescence intensity (between blank and experiments) at $\lambda_{\mathrm{em}} 458 \mathrm{~nm}$ with $\lambda_{\mathrm{ex}} 228$ to $\mathrm{CB}$ concentrations and the regression equation was computed.

\section{Analysis of laboratory prepared mixtures of $\mathrm{CB}$ and AQ}

-Methods (A), (B) and (C)

The absorption spectra of the laboratory prepared mixtures were recorded. Then the procedures were completed was described in subsection of Construction of the calibration curves. The concentrations of $\mathrm{CB}$ were calculated from the corresponding regression equations.

-Methods (D)

For AQ determination; the absorption spectra of the laboratory prepared mixtures were recorded. The procedure was performed as described under Construction of the calibration curves. The concentrations of $\mathrm{AQ}$ were calculated from regression equation (1).

For $\mathrm{CB}$ determination; the absorption spectra of the laboratory prepared mixtures were recorded at $280 \mathrm{~nm}$ (isoabsorptive point). Then the procedure was completed as described under Construction of the calibration curves. The total concentration of $\mathrm{CB}$ and AQ was calculated from the regression equation (2). The concentration of $\mathrm{CB}$ could be obtained after subtraction from the following equation: 
Citation: Ramadan NK, Mohamed TA, Fouad RM, Moustafa AA (2018) Development and Validation of Spectrophotometric and Spectrofluorimetric Methods for the Determination of Cyclobenzaprine HCl. Pharm Anal Acta 9: 574. doi: 10.4172/2153-2435.1000574

Page 3 of 10

$\mathrm{CB}$ concentration $=($ total concentration $-\mathrm{AQ}$ concentration $)$.

-Methods (E)

The fluorescence intensity of the laboratory prepared mixtures was recorded. Then the procedures were completed was described in subsection of Construction of the calibration curve. The concentrations of $\mathrm{CB}$ were calculated from the regression equation.

\section{Analysis of CB in pharmaceutical preparation}

Five Multirelax tablets were weighed accurately and powdered. An amount of equivalent to $100 \mathrm{mg}$ of $\mathrm{CB}$ was accurately weighed into $100-\mathrm{mL}$ volumetric flask and extracted with $50-\mathrm{mL}$ methanol using an ultrasonic bath for 30 minutes, diluted to volume with the same solvent and filtered. Into $50 \mathrm{~mL}$ of the filtered solution suitable dilutions were made using methanol to prepare tablet solution containing $1 \mathrm{mg} / \mathrm{mL}$ for methods (A), (B) (C) and (D). $2.5 \mathrm{~mL}$ of the solution was accurately transferred to a $10-\mathrm{mL}$ volumetric flask and was diluted to volume with methanol to prepare tablet solution containing $0.25 \mathrm{mg} / \mathrm{mL}$.

For method (D), the other $50 \mathrm{~mL}$ was evaporated to dryness, then dissolving the residue with $50 \mathrm{~mL}$ water and suitable dilutions were made using water to prepare tablet solution containing $0.1 \mathrm{mg} / \mathrm{mL}$. Then $0.4 \mathrm{~mL}$ accurately transferred into $10 \mathrm{~mL}$ volumetric flask, then the procedures were completed was described under Construction of the calibration curves. The concentration of $\mathrm{CB}$ was calculated from the corresponding regression equations.

\section{Results and Discussion}

This work is concerned with the simultaneous determination of CB in the presence of one degradation product $\mathrm{AQ}$ using spectrophotometric and spectrofluorimetric techniques. There were 5 stability methods previously published concerning with degradation product; only one was a spectrophotometric method dealing with 2 degradation mixture dibenzocycloheptatrienone and anthraquinone [29]. This work has an advantage over the published methods in sensitivity and specificity.

\section{Dual wavelength (DW)}

The developed dual wavelength method provides a simple spectrophotometric method for selective determination of $\mathrm{CB}$ in the presence of its degradation product AQ using its zero order absorption spectra; depending on that the absorbance difference at two wavelengths on the spectra is directly proportional to the concentration of the drug, with no interference from its degradation product [33-38]. To apply this method, only two wavelengths should be carefully chosen on the basis that the interfering component shows the same absorbance value and the component of interest shows significant difference in absorbance with concentration, The zero order absorption spectra of $\mathrm{CB}$ and its degradate $\mathrm{AQ}$ revealed great spectral overlap was shown in Figures 1 and 2.

Several trials have been made to select the optimum wavelengths for the drug. The best results regarding selectivity and sensitivity were obtained by using the absorbance difference at 283 and $306 \mathrm{~nm}$ for determination of $\mathrm{CB}$ where $\mathrm{AQ}$ has zero absorbance difference so no interference from $\mathrm{AQ}$ has been founded. The concentration of $\mathrm{CB}$ was calculated from the regression equation representing the linear relationship between the differences of the absorbance at the two selected wavelengths versus the corresponding concentration of drug.

A linear relationship was obtained in the range of $(5 \mu \mathrm{g} / \mathrm{ml}-30 \mu \mathrm{g} /$ $\mathrm{mL}$ ) of $\mathrm{CB}$ and the regression equation was computed, (Figure 3 ) and found to be:

\section{$\Delta \mathrm{P}_{(283-306)=} 0.0067 \mathrm{C}+0.0067 \mathrm{r}=0.9995$}

Where $\Delta \mathrm{P}_{(283-306)}$ is the difference in absorbance at 283 and $306, \mathrm{C}$ is the concentration of $\mathrm{CB}$ in $\mu \mathrm{g} / \mathrm{mL}$ and $\mathrm{r}$ is the correlation coefficient.

The proposed DW method was successfully applied for the determination of the drug in pure powder form with mean percentage recovery of $99.84 \pm 0.560$.

\section{Ratio difference (RD)}

The most advantage of the ratio difference method (RD) is its simplicity, accuracy and reproducibility. It has the ability of solving severely overlapped spectra without prior separation so it doesn't require any sophisticated apparatus or computer programs. This method depending on the amplitude difference between two points on the ratio spectra of a mixture is directly proportional to the concentration of the drug; independence of the interfering component (degradation product).

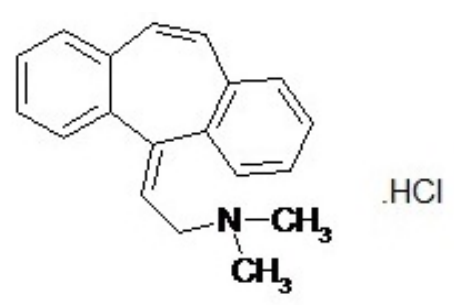

Figure 1: Chemical structure of CB.

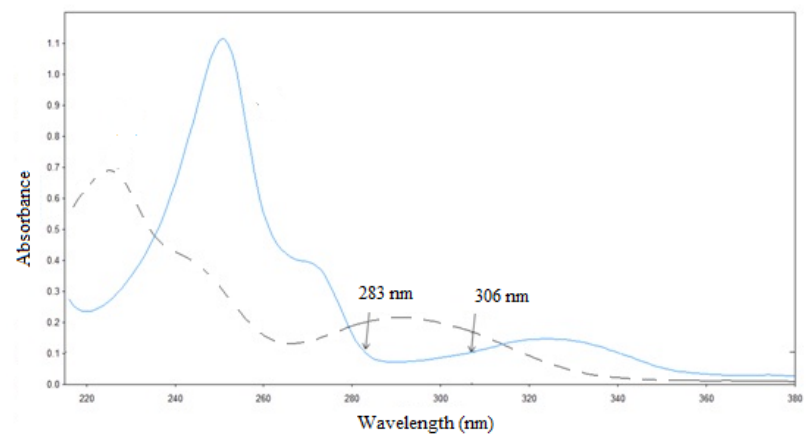

Figure 2: Zero order absorption spectra of $5.00 \mu \mathrm{g} / \mathrm{ml} \mathrm{cb}(-)$ and $5.00 \mu \mathrm{g} / \mathrm{ml}$ of aq (- - ) in methanol.

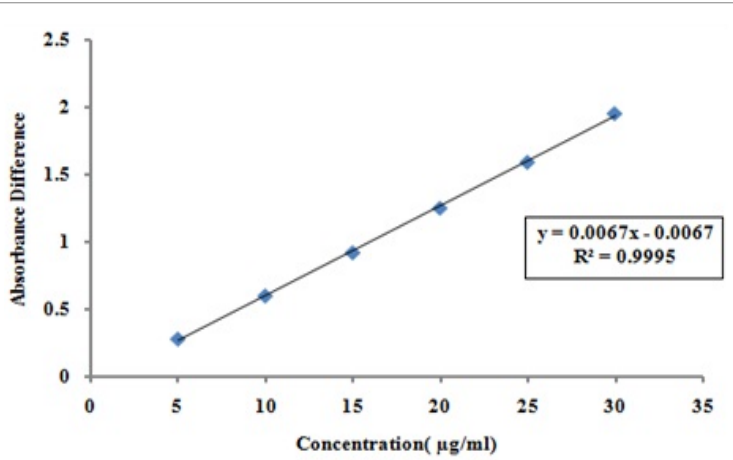

Figure 3: Linearity of the difference in absorbance at 283 and $306 \mathrm{~nm}$ to the corresponding concentrations of $\mathrm{cb}$ in methanol $(5.00-30.00 \mu \mathrm{g} / \mathrm{ml})$. 
Citation: Ramadan NK, Mohamed TA, Fouad RM, Moustafa AA (2018) Development and Validation of Spectrophotometric and Spectrofluorimetric Methods for the Determination of Cyclobenzaprine HCl. Pharm Anal Acta 9: 574. doi: 10.4172/2153-2435.1000574

The RD method has the main basic advantage over the DW of complete elimination of the interfering component (AQ) in the form of constant and the difference at any two points will be equal to zero, so there is no need for critical measurements which leads to highly reproducible and robust results [39-43].

The zero-order spectra of CB and its degradation product AQ show an overlap, (Figure 2), that prevents the use of direct spectrophotometric analysis of the drug in the presence of its degradation product. In an attempt to resolve this overlap, derivative method was applied. The ${ }^{1} \mathrm{D}$, ${ }^{2} \mathrm{D}$ and ${ }^{3} \mathrm{D}$ failed to be determined $\mathrm{CB}$ in the presence of its degradate (Figures 4 to 6).

The spectra of the CB were divided by a certain concentration of AQ spectrum was a divisor. The obtained ratio spectra are shown in Figure 7.

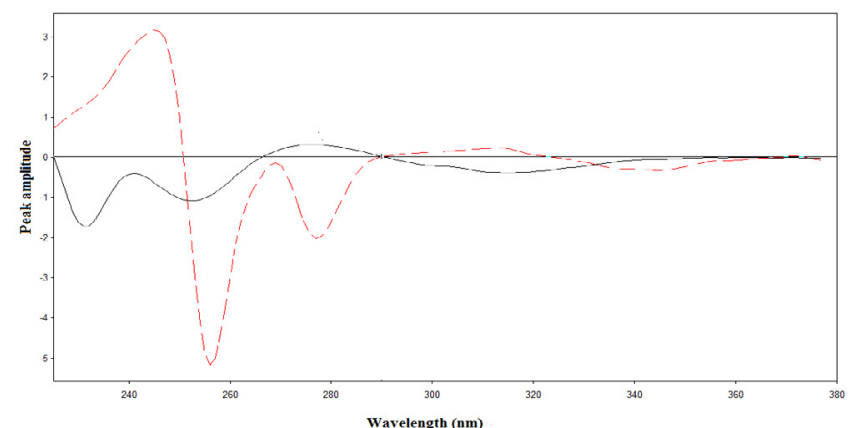

Figure 4: First derivative absorption spectra of $5.00 \mu \mathrm{g} / \mathrm{ml} \mathrm{cb}$ in methanol $(-)$ and $5.00 \mu \mathrm{g} / \mathrm{ml}$ of aq (-- -).

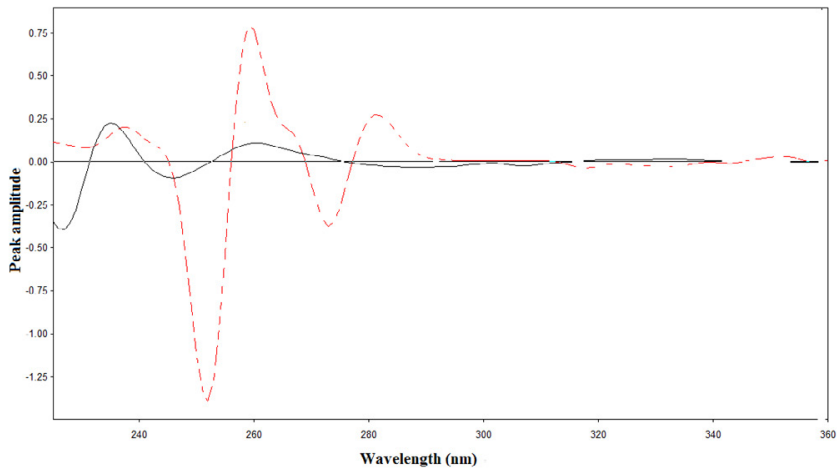

Figure 5: Second derivative absorption spectra $5.00 \mu \mathrm{g} / \mathrm{ml} \mathrm{cb}$ in methanol (-) and $5.00 \mu \mathrm{g} / \mathrm{ml}$ of aq (-- -).

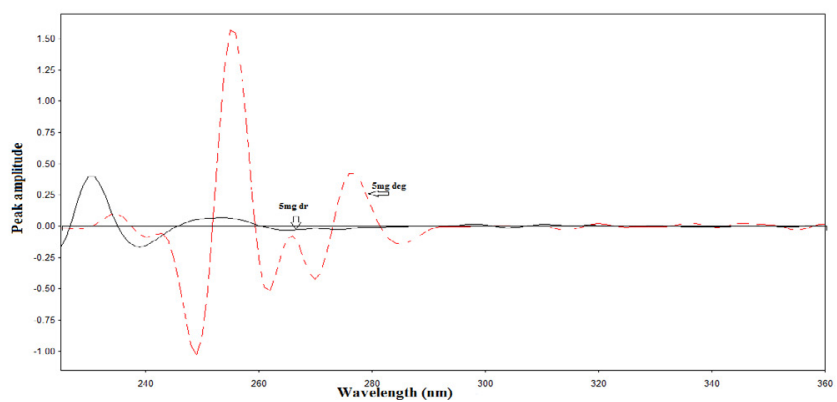

Figure 6: Third derivative absorption spectra $5.00 \mu \mathrm{g} / \mathrm{ml} \mathrm{cb}$ in methanol (-) and $5.00 \mu \mathrm{g} / \mathrm{ml}$ of aq (-- -).
The selected divisors should compromise between minimal noise and maximum sensitivity, so the divisors were chosen. The $\mathrm{CB}$ solutions $(5 \mu \mathrm{g} / \mathrm{mL}-30 \mu \mathrm{g} / \mathrm{mL})$ spectra were divided by the spectrum of its deg $(5 \mu \mathrm{g} / \mathrm{mL})$ and the concentration of $\mathrm{CB}$ was calculated by using the regression equation representing the linear relationship between the differences of these ratio spectra amplitudes at the two selected wavelengths versus the corresponding concentration of drug.

Linear relationship CB obtained in the range of $(5 \mu \mathrm{g} / \mathrm{ml}-30 \mu \mathrm{g} /$ $\mathrm{mL}$ ) of $\mathrm{CB}$, and the regression equation was computed (Figure 8) and found to be:

$$
\Delta \mathrm{P}_{(290-305)=} 0.0491 \mathrm{C}+0.0593 \mathrm{r}=0.9997
$$

Where $\Delta \mathrm{P}_{(290-305)}$ is the difference in peak amplitudes at 290 and $305 \mathrm{~nm}, \mathrm{C}$ is the concentration of $\mathrm{CB}$ in $\mu \mathrm{g} / \mathrm{mL}$ and $\mathrm{r}$ is the correlation coefficient.

The proposed RD method was successfully applied for the determination of the drug in pure powder form with mean percentage recovery of $100.22 \pm 0.509$.

\section{Derivative ratio spectrophotometry $\left({ }^{1} \mathrm{DD}\right)$}

Derivative spectrophotometry has been first suggested during the last decades and soon become a well-established technique for the assay of drugs in mixtures and in pharmaceutical dosage forms [44-45].

The derivative ratio spectrophotometry $\left({ }^{1} \mathrm{DD}\right)$ can also be applied to resolve the overlap between the drug and its degradation. The zeroorder absorption spectra of CB were divided by the spectrum of $5 \mu \mathrm{g} /$

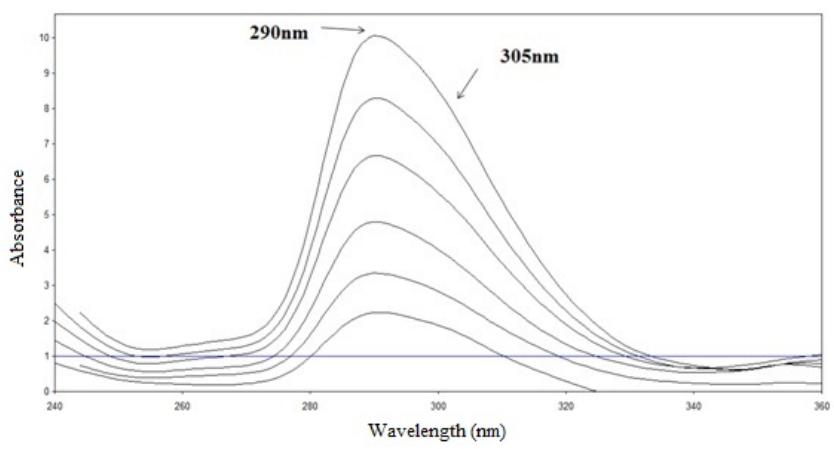

Figure 7: Zero order absorption spectra of ratio spectra of $5.00-30.00 \mu \mathrm{g} / \mathrm{ml} \mathrm{cb}$ (-) and $5.00 \mu \mathrm{g} / \mathrm{ml}$ of aq (- - ) in methanol using $5.00 \mu \mathrm{g} / \mathrm{ml}$ of aq as a divisor

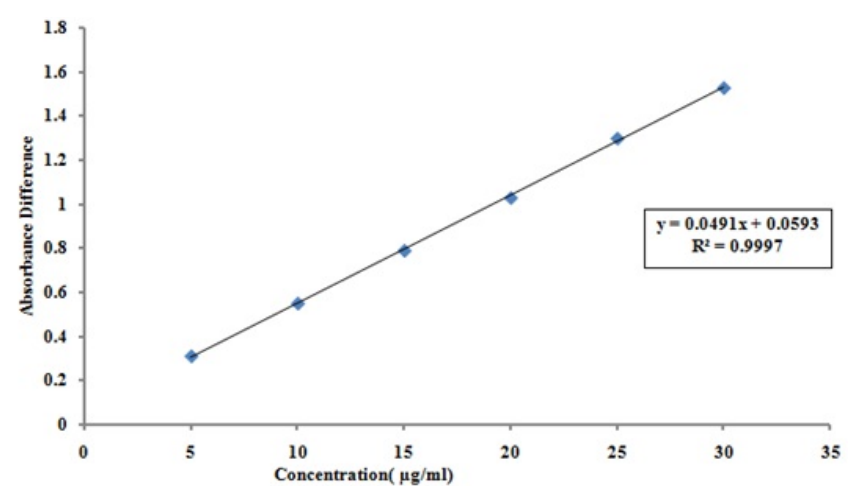

Figure 8: Linearity of the difference in absorbance at 290 and $305 \mathrm{~nm}$ of the ratio spectra to the corresponding concentrations of $\mathrm{cb}(5.00-30.00 \mu \mathrm{g} / \mathrm{ml})$ in methanol using $5.00 \mu \mathrm{g} / \mathrm{ml}$ of aq as a divisor. 
Citation: Ramadan NK, Mohamed TA, Fouad RM, Moustafa AA (2018) Development and Validation of Spectrophotometric and Spectrofluorimetric Methods for the Determination of Cyclobenzaprine HCl. Pharm Anal Acta 9: 574. doi: 10.4172/2153-2435.1000574

$\mathrm{mL}$ of its degradation product. This gave the best compromise in terms of sensitivity, repeatability, and signal-to noise ratio. The first derivative of the ratio spectra at 282 and $306 \mathrm{~nm}$ with $\Delta \lambda=2$ and scaling factor 10 were obtained. The peak amplitudes were measured at the selected wavelengths, (Figure 9).

The linearities between the concentrations of the drug and the peak amplitudes at the selected wavelengths were studied. Linear relationship obtained in the range of $(5 \mu \mathrm{g} / \mathrm{ml}-30 \mu \mathrm{g} / \mathrm{mL})$ of $\mathrm{CB}$, and the regression equations were computed (Figure 10) and found to be:

$$
\begin{aligned}
& { }^{1} \mathrm{DD}_{282}=1.5664 \mathrm{C}-0.2320 \mathrm{r}=0.9994 \\
& { }^{1} \mathrm{DD}_{306}=0.6748 \mathrm{C}-0.3473 \mathrm{r}=0.9993
\end{aligned}
$$

Where ${ }^{1} \mathrm{DD}_{282}$ and ${ }^{1} \mathrm{DD}_{303}$ are the peak amplitudes at 282 and 306 respectively, $\mathrm{C}$ is the concentration of $\mathrm{CB}$ in $\mu \mathrm{g} / \mathrm{mL}$ and $\mathrm{r}$ is the correlation coefficient.

The proposed ${ }^{1} \mathrm{DD}$ method $\mathrm{CB}$ was successfully applied for the determination of the drug in pure powder form with mean percentage recovery of $98.70 \pm 0.620$ and $100.27 \pm 0.528 \%$ at the $282 \mathrm{~nm}$ and 306 nm.

The isoabsorptive point is used for the analysis of two drugs in their binary formulation, by having the total concentration of both drugs, and then by the means of other method if the concentration of either drug could be determined separately, the concentration of the second one can be calculated by subtraction [46-51].

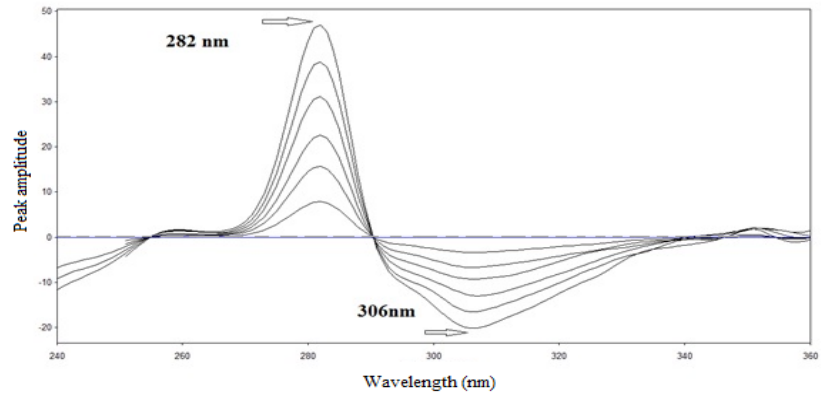

Figure 9: First derivative of ratio spectra ( $\left.{ }^{1} \mathrm{dd}\right)$ of $5.00-30.00 \mu \mathrm{g} / \mathrm{ml} \mathrm{cb}(-)$ and $5.00 \mu \mathrm{g} / \mathrm{ml}$ of aq (- - ) in methanol using $5.00 \mu \mathrm{g} / \mathrm{ml}$ of aq as a divisor.

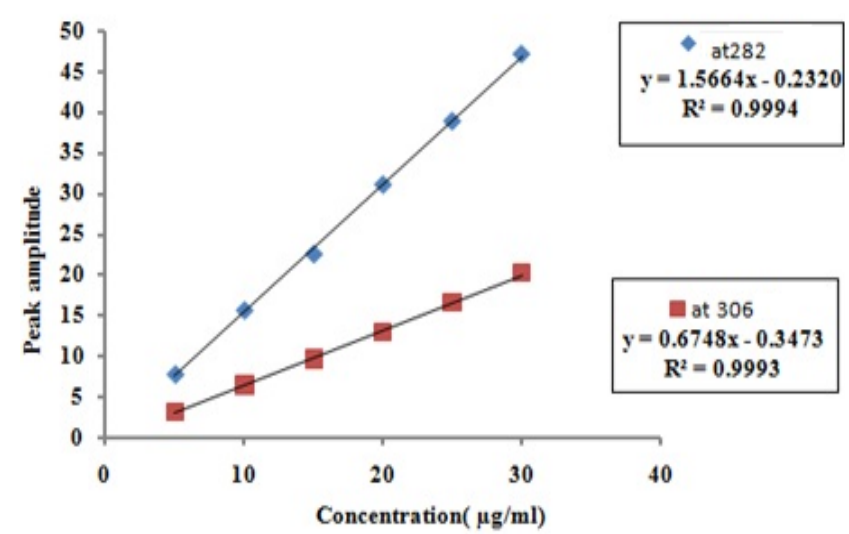

Figure 10: Linearities of the peak amplitude of the first derivative of ratio spectra to the corresponding concentrations of $\mathrm{cb}$ in methanol $(5.00-30.00$ $\mu \mathrm{g} / \mathrm{ml}$ ) using $5.00 \mu \mathrm{g} / \mathrm{ml}$ of aq as a divisor.
The theory of this method could be confirmed experimentally by recording the absorbance spectra of $\mathrm{CB}$ and $\mathrm{AQ}$ each having a concentration of $10 \mu \mathrm{g} / \mathrm{mL}$ and the spectrum of a mixture having a total concentration of $10 \mu \mathrm{g} / \mathrm{mL}(5 \mu \mathrm{g} / \mathrm{mL} \mathrm{CB}$ and $5 \mu \mathrm{g} / \mathrm{mL} \mathrm{AQ}$ ), (Figure 11).

In this figure, one can observe that the pure $\mathrm{CB}$ and $\mathrm{AQ}$ have their absorption spectra with an isoabsorptive point at $280 \mathrm{~nm}$. Meanwhile; their mixture has the same absorbance at their isoabsorptive point. According to the theory, that the mixture of $\mathrm{CB}$ and $\mathrm{AQ}$ act as a single component and give the same absorbance value as pure drug at their isoabsorptive point.

The total content of the mixture could be calculated as explained by the theory above by measuring the absorbance value at the chosen isoabsorptive point. The content of AQ alone could be calculated from its ${ }^{2} \mathrm{D}$ spectra at $250 \mathrm{~nm}$ without any interference from CB, (Figure 12). Then the content of $\mathrm{CB}$ could be calculated by subtraction.

It was found that, the first ( $\left.{ }^{1} \mathrm{D}\right)$ derivative, (Figure 13) failed to determine $\mathrm{AQ}$ in presence of $\mathrm{CB}$; upon applying the second derivatives, (Figure 12), zero crossing of CB was observed at $250 \mathrm{~nm}$, Therefore, ${ }^{2} \mathrm{D}$ was applied for the determination of AQ in presence of $\mathrm{CB}$.

The calibration curve relating the peak amplitudes of the second derivative absorption spectra of AQ at $250 \mathrm{~nm}$ to $\mathrm{AQ}$ concentrations was constructed, (Figure 14) and regression equation (1) was computed and found to be:

$$
{ }^{2} \mathrm{D}_{250=} 1.8127 \mathrm{C}_{\mathrm{AQ}}+8.9625 \mathrm{r}=1(1)
$$

Where, ${ }^{2} \mathrm{D}_{250}$ is the peak amplitude of the second derivative absorption spectra of AQ at $250 \mathrm{~nm}, \mathrm{C}_{\mathrm{AQ}}$ is the concentration of $\mathrm{AQ}$ in $\mu \mathrm{g} / \mathrm{mL}$ and $\mathrm{r}$ is the correlation coefficient.

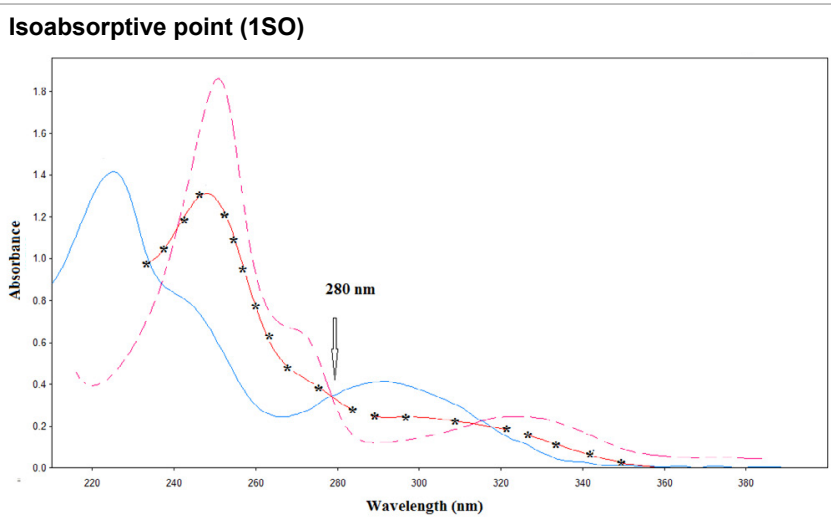

Figure 11: Zero order $\left({ }^{0} \mathrm{~d}\right)$ absorption spectra of $10.00 \mu \mathrm{g} / \mathrm{ml}$ of $\mathrm{cb}(-), 10.00$ $\mu \mathrm{g} / \mathrm{ml}$ aq (- - ) and mixture containing $5.00 \mu \mathrm{g} / \mathrm{ml}$ of $\mathrm{cb}$ and $5 \mu \mathrm{g} / \mathrm{ml} \mathrm{aq}{ }^{*}$ - $\left.{ }^{*}\right)$ showing isoabsorptive point at $280 \mathrm{~nm}$ using methanol as blank.

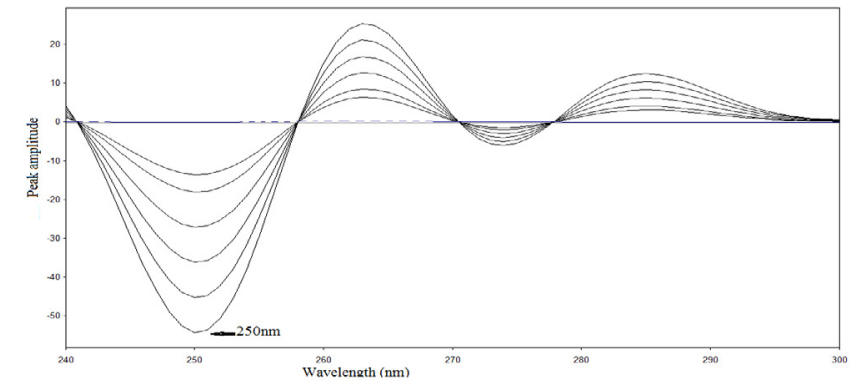

Figure 12: Second derivative absorption spectra of $2.50-25.00 \mu \mathrm{g} / \mathrm{ml}$ of aq (and $2.50 \mu \mathrm{g} / \mathrm{ml}$ of $\mathrm{cb}(---)$ using methanol as blank. 
Citation: Ramadan NK, Mohamed TA, Fouad RM, Moustafa AA (2018) Development and Validation of Spectrophotometric and Spectrofluorimetric Methods for the Determination of Cyclobenzaprine HCl. Pharm Anal Acta 9: 574. doi: 10.4172/2153-2435.1000574

Page 6 of 10

Also the calibration curve relating the absorbance at $280 \mathrm{~nm}$ (isoabsorptive point) of the zero-order absorption spectra of $\mathrm{CB}$ to the corresponding concentrations was constructed, (Figure 15) and regression equation (2) was computed and found to be:

\section{$\mathrm{A}_{\text {iso }=} 0.0367 \mathrm{C}_{\mathrm{T}}-0.0367 \mathrm{r}=0.9997(2)$}

Where, $\mathrm{A}_{\text {iso }}$ is the absorbance at $280 \mathrm{~nm}, \mathrm{C}_{\mathrm{T}}$ is the total concentration of the mixture in $\mu \mathrm{g} / \mathrm{mL}$ and $\mathrm{r}$ is the correlation coefficient.

The proposed method was found to be valid in the range of $2.5 \mu \mathrm{g} /$ $\mathrm{ml}-25 \mu \mathrm{g} / \mathrm{mL}$ for $\mathrm{AQ}$ and in the range of $5-30 \mu \mathrm{g} / \mathrm{mL}$ for $\mathrm{CB}$.

\section{Fluorimetric method}

Uranyl acetate has been used was a fluorogenic reagent; upon reacting with its fluorescence was quenched. This derivatization reaction [52-55] has been used for the determination of the cited drug by measuring the quenching of uranyl acetate fluorescence at $458 \mathrm{~nm}$

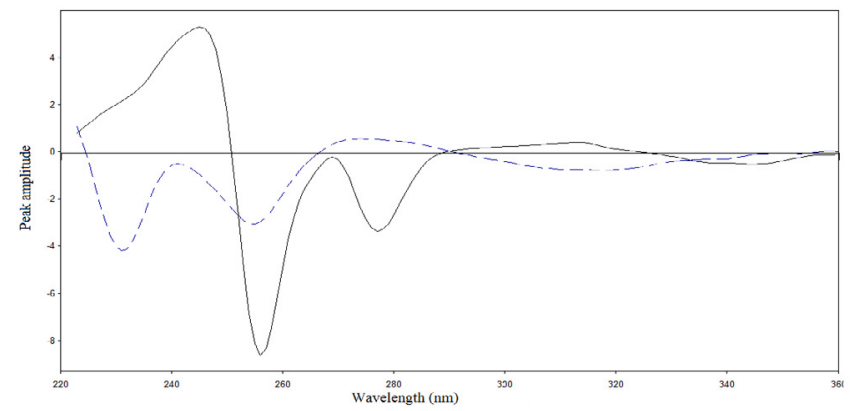

Figure 13: First order $\left({ }^{1} d\right)$ absorption spectra of aq (- ) and $\mathrm{cb}(---)$ using methanol as blank $(5.00 \mu \mathrm{g} / \mathrm{ml}$ of each).

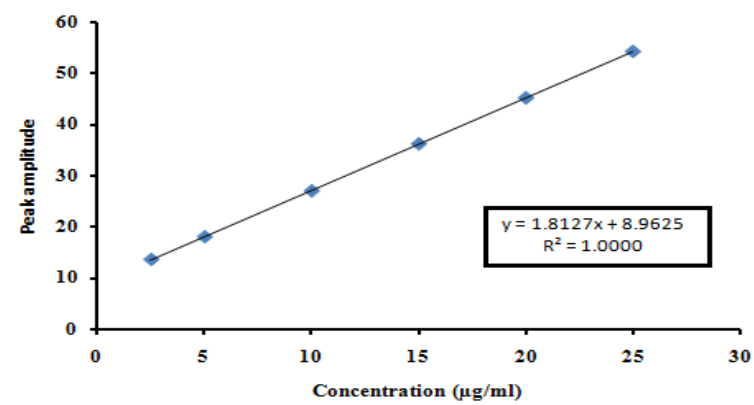

Figure 14: Linearity of the peak amplitudes of the second derivative spectra to the corresponding concentrations of aq $(2.50-25.00 \mu \mathrm{g} / \mathrm{ml})$ at $\lambda 250 \mathrm{~nm}$.

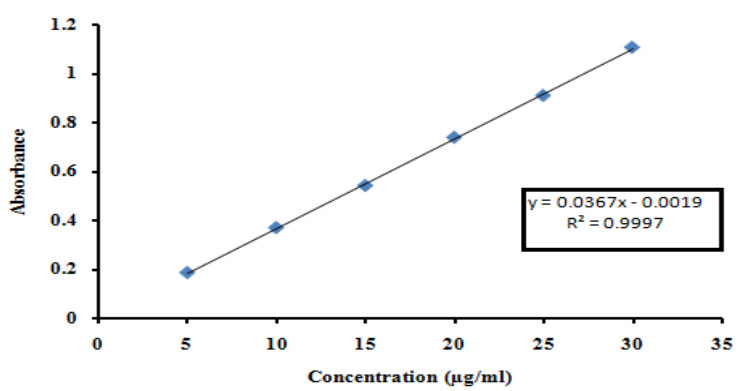

Figure 15: Linearity of absorbance at $280 \mathrm{~nm}$ (isoabsorptive point) of zeroorder absorption spectra to the corresponding concentrations of $\mathrm{cb}(5.00-30.00$ $\mu \mathrm{g} / \mathrm{ml})$. $\left(\lambda_{\text {ex }}=228 \mathrm{~nm}\right)$. The uranyl acetate solution has relative fluorescence intensity (Figure 16); upon the addition of $\mathrm{CB}$ the fluorescence intensity of the solution decreased significantly and the magnitude of the decrease was proportional to the concentration of CB, (Figure 17).

This would permit the determination of intact CB in presence its degradation product. The fluorescence intensity of different concentrations of $\mathrm{CB}$ in water was recorded against water as a blank, using 228 and $458 \mathrm{~nm}$ as excitation and emission wavelengths, respectively.

Various parameters affecting the reaction process, the reaction was found to be sensitive to volume of uranyl acetate $\left(0.25 \times 10^{-3} \mathrm{~mol}\right)$; $2.5 \mathrm{~mL}$ was found to be sufficient to produce maximum difference in fluorescence intensity. Also the stability of the difference in fluorescence intensity was studied and it was found that the intensity of the fluorescence difference was stable up to $60 \mathrm{~min}$. The fluorescence intensity was affecting significally by any organic solvent so water is the ideal solvent.

The stoichiometry of the reaction between $\mathrm{CB}$ and uranyl acetate was studied using the adopting limiting logarithmic [56] method as shown in Figure 18 and found one to one.

The difference in the fluorescence intensity was linear in the range of $1 \mu \mathrm{g} / \mathrm{mL}-10 \mu \mathrm{g} / \mathrm{mL}$, and the regression equation was computed (Figure 19) and found to be:

$$
\mathrm{I}_{\mathrm{f}}==50.9616 \mathrm{C}+453.5315 \mathrm{r}=0.9995
$$

Where $I_{f}$ is the difference in fluorescence intensity, $C$ is the concentration of $\mathrm{CB}$ in $\mu \mathrm{g} / \mathrm{mL}$ and $\mathrm{r}$ is the correlation coefficient

The proposed spectrofluorimetric method was successfully applied for the determination of $\mathrm{CB}$ with mean percentages recovery of 100.55 $\pm 0.447 \%$.

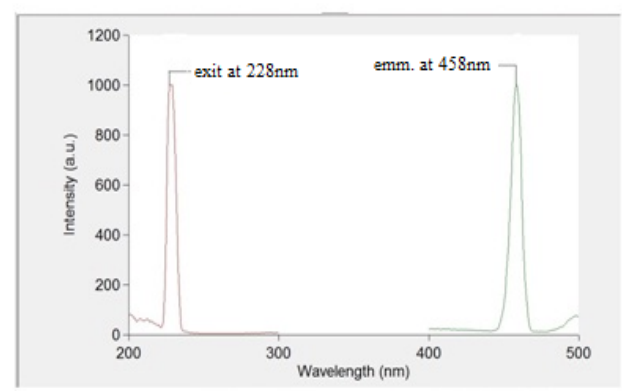

Figure 16: Excitation and emission spectra of uranyl acetate (blank) in wate at $\Lambda_{\mathrm{em}} 458 \mathrm{~nm}$ with $\Lambda_{\mathrm{ex}} 228 \mathrm{~nm}$.

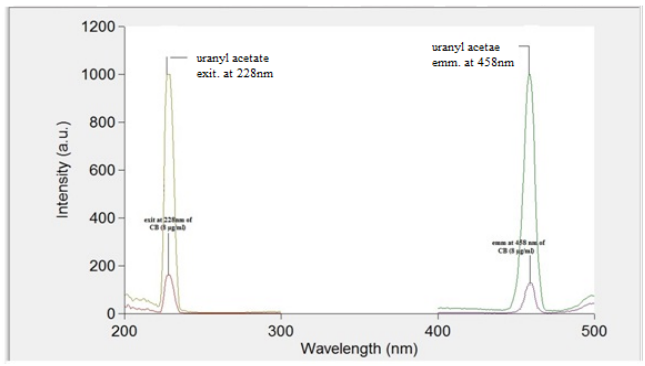

Figure 17: Excitation and emission spectra of the blank reagent (uranyl acetate) and the quenching effect of $\mathrm{cb}(8.00 \mu \mathrm{g} / \mathrm{ml})$ on the blank reagent. 
Citation: Ramadan NK, Mohamed TA, Fouad RM, Moustafa AA (2018) Development and Validation of Spectrophotometric and Spectrofluorimetric Methods for the Determination of Cyclobenzaprine HCl. Pharm Anal Acta 9: 574. doi: 10.4172/2153-2435.1000574

\section{Methods Validation}

Methods validation was performed according to ICH guideline [32] for the proposed methods as follows:

\section{Range and linearity}

The linearity of the proposed methods was evaluated by processing the different calibration curves on three different days. Each
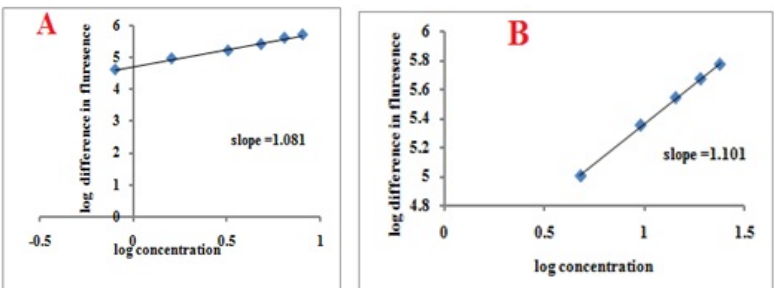

Figure 18: Stoichiometry of the Reaction Between $\mathrm{CB}$ and Uranyl Acetate Adopting Limiting Logarithmic Method; A-Variable CB Concentrations and Constant Uranyl Acetate Concentration B-Variable Uranyl Acetate Concentrations and Constant CB Concentration $(6.00 \mu \mathrm{g} / \mathrm{mL})$

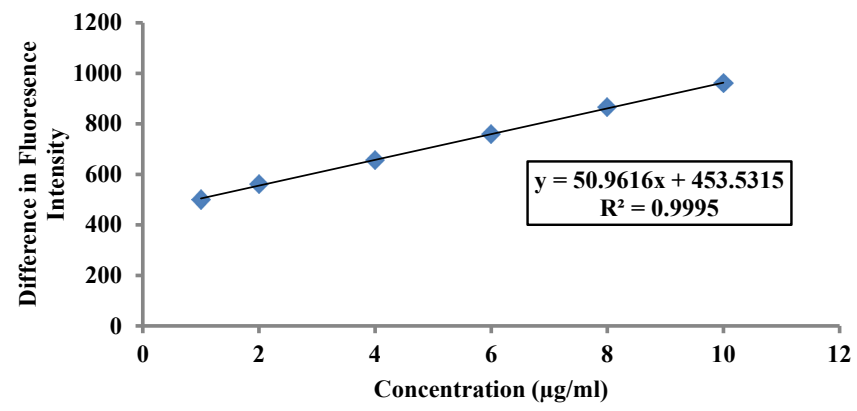

Figure 19: Linearity of the fluorescence intensity to the corresponding concentration of $\mathrm{cb}(1.00-10.00 \mu \mathrm{g} / \mathrm{ml})$ in water $\left(\right.$ at $\Lambda_{\mathrm{em}} 458 \mathrm{~nm}$ with $\left.\Lambda_{\mathrm{ex}} 228 \mathrm{~nm}\right)$. concentration was repeated in triplicate. The statistical parameters for all methods are listed in Table 1.

\section{Accuracy}

To study the accuracy of the proposed methods, the procedures under linearity for $\mathrm{CB}$, were repeated three times for the determination of three different concentrations of pure form. The accuracy expressed as percentage recoveries as shown in Table 1 .

\section{Precision}

The intra-day and inter-day precisions of the proposed methods were determined by the analysis of three different concentrations of $\mathrm{CB}$ three replicate on a single day and on three consecutive days, the results are illustrated in Table 1.

\section{Detection and quantification limits}

Limit of detections $(\mathrm{LOD}=3.3 \times \mathrm{SD} / \mathrm{b})$ and the limit of quantifications $(\mathrm{LOQ}=10 \times \mathrm{SD} / \mathrm{b})$ were calculated for $\mathrm{CB}$ using the proposed methods and the results are included in Table 1.

\section{Specificity and selectivity}

The specificity of the proposed methods was assessed by the analysis of a laboratory prepared mixture containing different percentages of AQ. Method (A) and (D) was found to be specific for CB in the presence of up to $70 \%$ of its degradate. Method (B) and (C) were found to be specific for CB till $90 \%$ in the presence of AQ. The specificity of method (E) was achieved in the presence of up to $50 \%$ of its degradate (Table 2).

\section{Robustness and ruggedness}

Small variations of the UV conditions and Fluorimetry were applied in order to determine the robustness of the methods. Analysis of $\mathrm{CB}$ at $25 \pm 3^{\circ} \mathrm{C}$ (different temperature) and using methanol from Sigma Aldrich (different company) did not have a significant effect on the UV spectra, illustrating excellent robustness of the methods.

\begin{tabular}{|c|c|c|c|c|c|c|}
\hline \multirow{3}{*}{ Parameters } & \multirow{3}{*}{$\begin{array}{l}\text { Method A } \\
\text { DW } \\
\Delta P(283-306)\end{array}$} & \multirow{3}{*}{$\begin{array}{l}\text { Method B } \\
\text { RD } \\
\Delta P(290-305)\end{array}$} & \multirow{2}{*}{\multicolumn{2}{|c|}{$\begin{array}{c}\text { Method C } \\
D^{1}\end{array}$}} & \multirow{3}{*}{$\begin{array}{l}\text { Method D } \\
\text { ISO } \\
\text { At } 280 \mathrm{~nm}\end{array}$} & \multirow{3}{*}{$\begin{array}{l}\text { Method E } \\
\text { Fluorimetry }\end{array}$} \\
\hline & & & & & & \\
\hline & & & At $282 \mathrm{~nm}$ & At $306 \mathrm{~nm}$ & & \\
\hline \multicolumn{7}{|c|}{ Validation of response } \\
\hline Linearity range $(\mu \mathrm{g} / \mathrm{ml})$ & $5.00-30.00$ & $5.00-30.00$ & $5.00-30.00$ & $5.00-30.00$ & $5.00-30.00$ & $1.00-10.00$ \\
\hline $\operatorname{LOD}(\mu \mathrm{g} / \mathrm{ml})$ & 1.110 & 1.230 & 0.750 & 0.920 & 3.277 & 0.280 \\
\hline $\mathrm{LOQ}(\mu \mathrm{g} / \mathrm{ml})$ & 3.360 & 4.000 & 2.270 & 2.790 & 1.230 & 0.850 \\
\hline $\begin{array}{c}\text { Accuracy } \\
\text { Mean } \pm \text { S.D\% }\end{array}$ & $99.84 \pm 0.598$ & $100.22 \pm 0.510$ & $98.70 \pm 0.612$ & $100.27 \pm 0.529$ & $99.20 \pm 0.612$ & $100.55 \pm 0.449$ \\
\hline \multirow{3}{*}{$\begin{array}{l}\text { Precision (Mean } \pm \text { S.D\%) } \\
\text { Repeatability }{ }^{* *} \\
\text { Intermediate precision }{ }^{* * *}\end{array}$} & & & & & & \\
\hline & $99.35 \pm 0.315$ & $100.35 \pm 0.115$ & $99.87 \pm 0.312$ & $100.43 \pm 0.434$ & $100.53 \pm 0.153$ & $99.87 \pm 0.324$ \\
\hline & $99.52 \pm 0.543$ & $100.72 \pm 0.213$ & $99.73 \pm 0.322$ & $99.65 \pm 0.456$ & $99.87 \pm 0.654$ & $99.23 \pm 0.832$ \\
\hline \multicolumn{7}{|c|}{ Validation of regression equation } \\
\hline Slope & 0.007 & 0.049 & 1.566 & 0.675 & 0.037 & 50.962 \\
\hline SE of slope & 0.001 & 0.001 & 0.020 & 0.009 & 0.003 & 0.578 \\
\hline Intercept & 0.007 & 0.059 & -0.232 & 0.347 & -0.002 & 453.532 \\
\hline SE of intercept & 0.015 & 0.009 & 0.389 & 0.176 & 0.007 & 3.506 \\
\hline Correlation coefficients & 0.9995 & 0.9997 & 0.9994 & 0.9993 & 0.9997 & 0.9995 \\
\hline SE of estimation & 0.016 & 0.010 & 0.417 & 0.189 & 0.007 & 4.506 \\
\hline \multicolumn{7}{|c|}{$\begin{array}{l}\text { Average of six determinations. } \\
\text { "Intra-day }(n=3) \text {, average of three concentrations of CB repeated } 3 \text { times within the same day } \\
\text { LOD: Limit of Detection; LOQ: Limit of Quantification, SD: Standard Deviation, SE: Standard Error }\end{array}$} \\
\hline
\end{tabular}

Table 1: Results of validation parameters obtained by the proposed methods for the determination of CB. 
Citation: Ramadan NK, Mohamed TA, Fouad RM, Moustafa AA (2018) Development and Validation of Spectrophotometric and Spectrofluorimetric Methods for the Determination of Cyclobenzaprine HCl. Pharm Anal Acta 9: 574. doi: 10.4172/2153-2435.1000574

Page 8 of 10

Three different concentrations of CB were analyzed in different lab using Shimadzu 1260 instead of Unicam and Shimadzu RF - 1501 instead of Agilant did not affect the UV and fluorescence spectra proved good ruggedness of the methods.

The proposed methods were also applied for the determination of CB in Multirelax tablet. The validity of the methods was assessed by applying the standard addition technique, as shown in Table 3 . From data obtained the mean percentage recoveries revealed that any excipients have no interference in the analysis of the pharmaceutical dosage forms. Statistical comparison between the results obtained by applying the proposed methods and that obtained by the official method [2] and there is no significant differences were found, as shown in Table 4.

\begin{tabular}{|c|c|c|c|c|c|c|c|c|c|c|}
\hline \multirow{3}{*}{$\underset{\%}{\text { Degree }}$} & \multicolumn{7}{|c|}{ Methods (A), (B), (C) and (D) } & \multicolumn{3}{|c|}{ Method (E) Fluorimetry } \\
\hline & \multirow{2}{*}{$\begin{array}{c}\mathrm{CB}(\mu \mathrm{g} / \\
\mathrm{mL})\end{array}$} & \multirow{2}{*}{$\begin{array}{c}\mathrm{AQ} \\
(\mu \mathrm{g} / \mathrm{mL})\end{array}$} & \multirow{2}{*}{$\begin{array}{c}\begin{array}{c}\text { Recovery* } \\
\text { \% of DW method }\end{array} \\
\Delta \mathrm{P} \\
(283-306)\end{array}$} & \multirow{2}{*}{$\begin{array}{c}\text { Recovery\% of RD } \\
\text { method }\end{array}$} & \multicolumn{2}{|c|}{$\begin{array}{c}\text { Recovery } \% \\
\text { of } D D^{1} \\
\text { method }\end{array}$} & \multirow{2}{*}{$\begin{array}{l}\text { Recovery\% of } \\
\text { ISO method } \\
\text { At } 280 \mathrm{~nm}\end{array}$} & \multirow{2}{*}{$\begin{array}{c}\text { CB } \\
(\mu \mathrm{g} / \mathrm{mL})\end{array}$} & \multirow{2}{*}{$\begin{array}{c}A Q \\
(\mu \mathrm{g} / \mathrm{mL})\end{array}$} & \multirow{2}{*}{$\begin{array}{c}\text { Recovery } \\
\%\end{array}$} \\
\hline & & & & & At $262 \mathrm{~nm}$ & At $306 \mathrm{~nm}$ & & & & \\
\hline 10 & 25.00 & 5.00 & 99.6 & 99.73 & 98.98 & 99.63 & 99.72 & 9.00 & 1.00 & 99.9 \\
\hline 30 & 20.00 & 10.00 & 99.85 & 99.76 & 99.63 & 100.37 & 99.35 & 7.00 & 3.00 & 100.43 \\
\hline 50 & 15.00 & 15.00 & 100.33 & 100.05 & 98.71 & 100.96 & 100.47 & 5.00 & 5.00 & 100.99 \\
\hline 70 & 10.00 & 20.00 & 100.9 & 100.34 & 98.93 & 100.52 & 100.8 & 3.00 & 7.00 & $105^{*}$ \\
\hline 90 & 5.00 & 25.00 & $106^{* * *}$ & 100.86 & 98.37 & 99.87 & $110^{* * *}$ & 1.00 & 9.00 & \\
\hline Mean & & & 100.17 & 100.15 & 98.924 & 100.27 & 100.09 & & & 100.44 \\
\hline$\pm \mathrm{SD} \%$ & & & 0.572 & 0.468 & 0.467 & 0.528 & 0.666 & & & 0.543 \\
\hline
\end{tabular}

Table 2: Results of analysis of $C B$ in laboratory prepared mixtures containing different ratios of $C B$ and $A Q$ by the proposed methods.

\begin{tabular}{|c|c|c|c|c|c|c|c|c|}
\hline $\begin{array}{l}\text { Pharmaceutical } \\
\text { formulation }\end{array}$ & \multirow{2}{*}{$\begin{array}{l}\text { Standard } \\
\text { added }(\mu \mathrm{g} / \\
\mathrm{mL})\end{array}$} & \multirow{2}{*}{$\begin{array}{c}\begin{array}{c}\text { Method A } \\
\text { (DW) }\end{array} \\
\text { Recovery \% }\end{array}$} & \multirow{2}{*}{$\begin{array}{l}\text { Method B (RD) } \\
\text { Recovery } \%\end{array}$} & \multicolumn{2}{|c|}{$\begin{array}{l}\text { 'Method C' } \\
\left(D^{1}\right)^{\prime}\end{array}$} & \multirow{2}{*}{$\begin{array}{c}\begin{array}{c}\text { Method D } \\
\text { (ISO) }\end{array} \\
\text { Recovery \% }\end{array}$} & \multicolumn{2}{|c|}{$\begin{array}{l}\text { 'Method E } \\
\text { Fluorimetry }\end{array}$} \\
\hline \multirow{5}{*}{$\begin{array}{l}\text { Multi-relax } \\
\text { tablets, (B. No } \\
\text { CBP/1506004-M) }\end{array}$} & & & & $\begin{array}{l}\text { Recovery } \% \text { at } \\
\text { 282nm }\end{array}$ & $\begin{array}{c}\text { Recovery }{ }^{* *} \% \text { at } \\
306 \mathrm{~nm}\end{array}$ & & $\begin{array}{l}\text { Standard } \\
\text { added }(\mu g / \\
\quad \mathrm{mL})\end{array}$ & Recovery ${ }^{* *} \%$ \\
\hline & 5.00 & 99.40 & 100.83 & 99.76 & 100.13 & 99.90 & 2.00 & 100.54 \\
\hline & 10.00 & 98.90 & 100.62 & 99.83 & 100.75 & 100.90 & 4.00 & 100.67 \\
\hline & 20.00 & 99.95 & 100.55 & 100.72 & 100.93 & 99.60 & 6.00 & 100.31 \\
\hline & $\begin{array}{l}\text { Mean } \pm \\
\text { SD } \%\end{array}$ & $\begin{array}{c}99.42 \\
\pm 0.832\end{array}$ & $\begin{array}{l}100.67 \\
\pm 0.118\end{array}$ & $\begin{array}{l}100.10 \\
\pm 0.534\end{array}$ & $\begin{array}{l}100.60 \\
\pm 0.417\end{array}$ & $\begin{array}{l}100.13 \\
\pm 0.555\end{array}$ & $\begin{array}{l}\text { Mean } \pm \\
\text { SD\% }\end{array}$ & $\begin{array}{l}100.51 \\
\pm 0.181\end{array}$ \\
\hline \multicolumn{2}{|c|}{$\begin{array}{c}\text { Found\% * of Claimed amount } \\
\pm \text { S.D }\end{array}$} & $99.60 \pm 0.610$ & $100.13 \pm 0.538$ & $100.11 \pm 0.559$ & $100.22 \pm 0.246$ & $99.38 \pm 0.828$ & \multicolumn{2}{|c|}{$100.66 \pm 0.215$} \\
\hline \multicolumn{9}{|c|}{$\begin{array}{l}\text { Claimed amount } 10.00(\mu \mathrm{g} / \mathrm{mL}) \text { in method } \mathrm{A}, \mathrm{B}, \mathrm{C} \text { and } \mathrm{D} \text { while } 4.00(\mu \mathrm{g} / \mathrm{mL}) \text { in method } \mathrm{E} \\
{ }^{*} \text { Average of five determination } \\
\text { "Average of three determination }\end{array}$} \\
\hline
\end{tabular}

Table 3: Quantitative determination of CB in pharmaceutical formulations by the proposed methods and results of application of standard addition technique.

\begin{tabular}{|c|c|c|c|c|c|c|c|}
\hline \multirow[t]{2}{*}{ Item } & \multirow{2}{*}{$\begin{array}{c}\text { Method (A) } \\
\text { DW }\end{array}$} & \multirow{2}{*}{$\begin{array}{c}\text { Method (B) } \\
\text { RD }\end{array}$} & \multicolumn{2}{|c|}{$\begin{array}{c}\text { Method }(\mathbf{C}) \\
D D^{1}\end{array}$} & \multirow{2}{*}{$\begin{array}{c}\text { Method (D) } \\
\text { ISO } \\
\text { At 280nm }\end{array}$} & \multirow{2}{*}{$\begin{array}{l}\text { Method (E) } \\
\text { Fluorimetry }\end{array}$} & \multirow{2}{*}{$\begin{array}{c}\text { Official } \\
\text { Method }^{(*)}\end{array}$} \\
\hline & & & At $282 \mathrm{~nm}$ & At $306 \mathrm{~nm}$ & & & \\
\hline Mean & 99.84 & 100.22 & 98.70 & 100.27 & 99.20 & 100.55 & 99.50 \\
\hline S.D. & 0.598 & 0.510 & 0.612 & 0.529 & 0.612 & 0.449 & 0.328 \\
\hline R.S.D. \% & 0.560 & 0.509 & 0.620 & 0.528 & 0.617 & 0.448 & 0.330 \\
\hline Variance & 0.358 & 0.260 & 0.375 & 0.280 & 0.375 & 0.202 & 0.108 \\
\hline $\mathrm{n}$ & 6 & 6 & 6 & 6 & 6 & 6 & 6 \\
\hline Student's t (2.228) & 0.344 & 0.756 & 0.805 & 0.802 & 0.781 & 1.133 & \\
\hline $\mathrm{F}$ test $(6.260)$ & 3.315 & 2.407 & 3.472 & 2.593 & 3.468 & 1.870 & \\
\hline
\end{tabular}

Official method non aqueous titration [2]

SD: Standard Deviation, RSD: Relative Standard Deviation

${ }_{* *}$ Figures in parentheses are the corresponding tabulated values at $p=0.05$

Table 4: Statistical comparison between the results obtained for the determination of CB in pure samples by the proposed methods and that obtained by the official method ( ${ }^{*}$. 
Citation: Ramadan NK, Mohamed TA, Fouad RM, Moustafa AA (2018) Development and Validation of Spectrophotometric and Spectrofluorimetric Methods for the Determination of Cyclobenzaprine HCl. Pharm Anal Acta 9: 574. doi: 10.4172/2153-2435.1000574

\section{Conclusion}

The five suggested methods have many advantages of being simple, accurate, precise, sensitive and inexpensive. These methods could be applied in quality control laboratories for quantitative determination of $\mathrm{CB}$, in pure form, in its formulation and in the presence of $\mathrm{AQ}$ (its degradation product). The presented fluorimetric method could provide a highly sensitive method for the determination of $\mathrm{CB}$ than spectrophotometric methods; even the RD and ${ }^{1} \mathrm{DD}$ methods were more specific than the other methods.

\section{References}

1. Martindale (2002) The Complete Drug Reference. 3rd edn. Pharmaceutical Press, UK

2. U.S. Pharmacopeia (2007) U.S. Pharmacopeial Convention, Inc., USA.

3. Moffat AC, Osselton MD, Widdop B (2004) Clarke's analysis of drugs and poisons: In pharmaceuticals, body and postmortem material. Pharmaceutical Press, UK.

4. Kaasem AM, Guesmi NE (2016) Sensitive kinetic spectrophotometric determination of cyclobenzaprine $\mathrm{Hcl}$ in pure form and pharmaceutical formulations. Anal Chem Lett 6: 657-668.

5. Kumar TV, Seethamma M, Venkateshwarlu G (2014) Quantitative determination of drugs \& pharnaceuticalsby using iodine as analytical reagent: A spectrophotometric study. IOSR-JAC 7: 7-15

6. Matsui F, French WN (1971) Analysis of binary mixtures of pharmaceutical amines by the acid dye technique. J Pharm Sci 60: 287-291.

7. Faber DB (1972) Separation of cyclobenzaprine from biological samples and its determination by thin-layer chromatography followed by densitometry. J Chromatog A 74: 85-98

8. Hardea MT, Wankhedeb SB, Chaudharia PD (2016) Validated inherent stability indicating HPTLC method for estimation of cyclobenzaprine hydrochloride in tablets and use of MS-QTOF in characterization of its alkaline stress degradation product. Bull Facul Pharm 54: 145-156.

9. Heinitz ML (1982) Determination of cyclobenzaprine in tablets by highperformance liquid chromatography. J Pharm Sci 71: 656-658.

10. Constanzer M, Chavez C, Matuszewski BK (1995) Development and comparison of high-performance liquid chromatographic methods with tandem mass spectrometric and ultraviolet absorbance detection for the determination of cyclobenzaprine in human plasma and urine. J Chromatogr B 666: 117-126.

11. Holeman JA, Danielson ND (1995) Microbore liquid chromatography of tertiary amine anticholinergic pharmaceuticals with tris (2,2'-bipyridine) ruthenium(III) chemiluminescence detection. J Chromatogr Sci 33: 297-302.

12. Ryan TW (1993) Identification and quantification of tricyclic antidepressants by UV-photodiode array detection with multicomponent analysis. J Liq Chromatogr Rel Tech 16: 1545-1560.

13. Hwang PT, Young DA, Straughn AB, Meyer MC (1993) Quantitative determination of cyclobenzaprine in human plasma by high pressure liquid chromatography. J Liq Chromatogr 16: 1163-1171.

14. Roshni DP, Usmangani KC, Falgun AM, Dimal AS, Kashyap KB (2014) Liquid chromatographic estimation of cyclobenzaprine hydrochloride and aceclofenac in pharmaceutical formulation. RRJPPS 3: 37-44.

15. Yu W, Yang X, Sui W, Xu H, Luan X, et al. (2014) Rapid and sensitive analysis of cyclobenzaprine by LC-MS/MS: Application to a pharmacokinetic study of cyclobenzaprine in dog. Asian J Pharm Sci 9: 117-122.

16. Herrin GL, McCurdy HH, Wall WH (2005) Investigation of an LC-MS-MS (QTrap) method for the rapid screening and identification of drugs in postmortem toxicology whole blood samples. J Anal Toxicol 29: 599-606.

17. Wong EC, Koenig J, Turk J (1995) Potential interference of cyclobenzaprine and norcyclobenzaprine with HPLC measurement of amitriptyline and nortriptyline: Resolution by GC-MS analysis. J Anal Toxicol 19: 218-224.

18. Li JC, Chen FH, Zhang JD, Dong HJ, Gao S (2012) A sensitive, fast and accurate liquid chromatographyelectrospray ionization-tandem mass spectrometry (LCMS/MS) method for the pharmacokinetic study of cyclobenzaprine tablets. Afr J Pharm Pharmacol 6: 708-716.
19. Koves EM (1995) Use of high-performance liquid chromatography-diode array detection in forensic toxicology. J Chromatogr A 692: 103-119.

20. Xiang Y, Zhou L, Qian Z, Peng K, Li D, et al. (2012) Determination of cyclobenzaprine in human plasma by liquid chromatography electrospray ionization tandem mass spectrometry and its application in a pharmacokinetic study. Biomed Chromatogr 26: 1083-1088.

21. Liu Y, Zhao D, Zhongxi Z (2014) Study of degradation mechanisms of cyclobenzaprine by LC-MS/MS. Anal Methods 6: 2320-2330.

22. Coulter C, Taruc M, Tuyay J, Moore C (2010) Antidepressant drugs in oral fluid by liquid chromatography-tandem mass spectrometry. J Anal Toxicol 34: 64-72.

23. Constanzer ML, Vincek WC, Bayne WF (1985) Determination of cyclobenzaprine in plasma and urine using capillary gas chromatography with nitrogen-selective detection. J Chromatogr 339: 414-418.

24. Schember I, Bailey K, Kraner J, Richards-Waugh L (2007) Validation of a GC/ MS method for the determination of alkaline drugs in whole blood. Forensic Sci Int 165: 216-224

25. Hucker HB, Stauffer SC (1976) Gas-liquid chromatographic determination of nanogram amounts of cyclobenzaprine in plasma using a nitrogen detector. $J$ Chromatogr 124: 164-168.

26. Hucker HB, Stauffer SC (1976) GLC determination of cyclobenzaprine in plasma and urine. J Pharma Sci 65: 1253-1255.

27. Ramadan NK, Zaazaa HE, Merey HA (2011) Microsized graphite sensors for potentiometric determination of cyclobenzaprine hydrochloride in pure powder, tablets, and plasma. J AOAC Int 94: 1807-1814.

28. Harde MT, Wankhede SB, Chaudhari PD (2016) A validated inherent stability indicating HPTLC method for estimation of cyclobenzaprine hydrochloride in tablets and use of MS-QTOF in characterization of its alkaline stress degradation product. Bull Faculty Pharm 54: 145-156.

29. Naguib IA, Abdelaleem EA, Abdallah FF, Ali NW (2016) Development and validation of three spectrophotometric methods for determination of Cyclobenzaprine $\mathrm{Hcl}$ in the presence of its two major degradation products. Anal Chem Lett 6: 24-34

30. Cioroiu BI, Grigoriu IC, Cioroiu ME, Niculaua M, Lupuleasa R, et al. (2016) Determination of degradation products of Cyclobenzaprine Hydrochloride, Lidocaine and Piroxicam in a semi-topical formulation: MS-MS confirmation of unknown impurities. J Chromatogr Sci 54: 902-911.

31. Ramadan NK, Mohamed TA, Fouad RM, Moustafa AA (2017) Stability-indicating HPLC and TLC chromatographic methods for determination of cyclobenzaprine hydrochloride and asenapine maleate. JPC $30: 313-322$

32. ICH, Q2 (R1) ( 2005) Validation of Analytical Procedures: Text and Methodology, $\mathrm{ICH}$ Harmonized Tripartite Guideline.

33. Kant RAVI, BODLA R, KAPOOR G, BHUTANI R (2016) Development and validation of novel spectrophotometric methods for simultaneous estimation of pioglitazone and metformin in bulk and fixed dosage forms by area under the curve and dual wavelength mode. Int J Appl Pharm 8: 48-53.

34. Topagi KS, Sinha PK, Jeswani RM, Damle MC (2009) Spectrophotometric methods for simultaneous estimation of diacerhein and aceclofenac. Int $J$ Chem Tech Res 1: 991-995.

35. Abdelrahman MM (2013) Simultaneous determination of Cinnarizine and Domperidone by area under curve and dual wavelength spectrophotometric methods. Spectrochimica Acta Part A: Mol Biomol Spectroscopy 113: 291-296.

36. Abdelwahab NS, Ali NW, Abdelkawy MM (2014) Different spectrophotometric and TLC-densitometric methods for determination of two analgesic drugs Asian J Biomed Pharm Sci 4: 26-33.

37. Abdelrahman MM, Naguib IA, El Ghobashy MR, Ali NA (2015) Quantitative determination of zopiclone and its impurity by four different spectrophotometric methods. Spectrochimica Acta Part A: Mol Biomol Spectroscopy 137: 617-624.

38. Lotfy HM, Hegazy MAM (2013) Simultaneous determination of some cholesterol-lowering drugs in their binary mixture by novel spectrophotometric methods. Spectrochimica Acta Part A: Mol Biomol Spectroscopy 113: 107-114.

39. Elzanfaly ES, Saad AS, Abd-Elaleem AEB (2012) Simultaneous determination of retinoic acid and hydroquinone in skin ointment using spectrophotometric technique (ratio difference method). Saudi Pharm J 20: 249-253.

40. Elzanfaly E, Saadand A, Abd-Elaleem A (2012) A novel simple method for 
Citation: Ramadan NK, Mohamed TA, Fouad RM, Moustafa AA (2018) Development and Validation of Spectrophotometric and Spectrofluorimetric Methods for the Determination of Cyclobenzaprine HCl. Pharm Anal Acta 9: 574. doi: 10.4172/2153-2435.1000574

resolving overlapped spectral data with a wide range of applicability, and its application as a stability indicating method for determination of tazarotene. Pharm Anal Acta 3: 153-156.

41. Ankit S, Mukesh G, Vaishali T, Lalji B, Tejal G (2014) Simultaneous determination of moxifloxacin hydrochloride and difluprednate by ratio derivative spectrophotometry. IJPPs 6: 387-390

42. Lotfy HM, Hagazy MAM (2012) Comparative study of novel spectrophotometric methods manipulating ratio spectra: An application on pharmaceutical ternary mixture of omeprazole, tinidazole and clarithromycin. Spectrochim Acta A Mol Biomol Spectrosc 96: 259-270.

43. Samir A, Lotfy HM, Salem H, Abdelkawy M (2014) Development and validation of simultaneous spectrophotometric and TLC-spectrodensitometric methods for determination of beclomethasone dipropionate and salbutamol in combined dosage form. Spectro Acta Part A 128: 127-136.

44. Altinös S, Tekeli D (2001) Analysis of glimepiride by using derivative UV spectrophotometric method. J Pharm Biomed Anal 24: 507-515.

45. Salinas F, Nevado JJB, Espinosa MA (1990) A new spectrophotometric method for quantitative multicomponent analysis resolution of mixtures of salicylic and salicyluric acids. Talanta 37: 347-351.

46. Erram SV, Tipnis HP (1993) Simple spectrophotometric analysis of acebutano hydrochloride and atenolol in combined pharmaceutical dosages with hydrochlorothiazide. Indian Drugs 30(7): 319-323.

47. Erram SV, Tipnis HP (1993) Simple spectrometric analysis of frusemide and amiloride hydrochloride from combined pharmaceutical dosages. Indian Drugs 30: $371-376$
48. Erram SV, Tipnis HP (1994) Simple spectrometric analysis of propranolo hydrochloride and hydrochlorothiazide from combined pharmaceutical dosages. Indian Drugs 31: 65-68.

49. Erram SV, Tipnis HP (1993) Simple spectrometric analysis of acebutolo hydrochloride and atenolol in combined pharmaceutical dosages with hydrochlorothiazide. Indian Drugs 30:462-467.

50. Connors AK (1967) Pharmaceutical Analysis. Wiley, USA.

51. Abd EL-Hafez MT, El-Ragehy NA, Ramadan NK, El-Zeany BE (2015) Simultaneous determination of a binary mixture of pantoprazole sodium and itopride hydrochloride by four spectrophotometric methods. Spectro Acta part A 137: 463-470.

52. El-Reis MA (1998) Determination of piroxicam in pharmaceutical preparations by continuous-flow chemiluminescence. J Anal Lett 31: 793.

53. Sah U, Sen AK, Das TK (1988) Spectrophotometric determination of clioquinol and diodoquin in pharmaceutical preparations using uranyl acetate as a chromogenic agent. Analyst 113: 1653-1655.

54. Sărbu C, Horn M, Hantz A (1985) Uranylsalze als fluoreszenzindikatoren für den dünnschichtchromatographischen Nachweis von komplexbildner. J Chromatogr A 322: 272-274.

55. Taha EA, Hassan NY, Aal FA, Abdel Fattah LE (2007) Fluorimetric determination of some sulfur containing compounds through complex formation with terbium $\left(\mathrm{Tb}^{+3}\right)$ and uranium $\left(\mathrm{U}^{+3}\right)$. J Fluoresc 17:293-300.

56. Rose J (1964 ) Advanced Physicochemical Experiments. Pitam, UK. 